\title{
Upaya dan Kendala Konselor Puskesmas dalam Perawatan Pasien Skizofrenia
}

\author{
Rendi Editya Darmawan ${ }^{1 *}$, Sudiro ${ }^{2}$ \\ ${ }^{1,2}$ Poltekkes Kemenkes Surakarta Jurusan Keperawatan \\ *Email: rendiedityad@gmail.com
}

\begin{abstract}
Background: Schizophrenia is a severe mental disorder and chronic affecting 20 million people worldwide. Schizophrenia is characterized by impaired language, sense of self, and behavior distortions in thinking, perception, and emotions. Some case includes delusions (fixed, false beliefs) and hallucinations (hearing voices or seeing things that are not there). Schizophrenia is a treatable disease with psychosocial support and medicines are effective. The role of the public health service counselor is important to give psychosocial support and medicines to the patient. Aim of this study to describe efforts and constraints public health care counselor in the care of schizophrenic patients. Methods: A descriptive qualitative study with 4 informants from public health service counselor. Purposive sampling is used to selecting informants. Analyze of data was carried out qualitatively. The triangulation of sources, methods, researchers, and theories is used to test validity. The study was conducted in January-November 2019, in Pilang Kenceng Village, Madiun Regency. Data collection was carried out by in-depth interviewing using guide questions. Results: The results showed that there were 6 themes in answering research objectives are submission of training, optimizing the role of the community, early detection, providing treatment, counseling, and constraints. Conclusion: Efforts made by counselors have not been running optimally because of the synergy and communication with the community is not going well. Constraints in efforts in the care of schizophrenic patients support from the government that is minimum.
\end{abstract}

Keyword: care, role of counselor, schizophrenia

\section{PENDAHULUAN}

Skizofrenia adalah gangguan mental seumur hidup dimana dapat menurunkan kemampuan seseorang didalam melakukan aktifitas pemenuhan kebutuhan sehari-hari (Sumner, Selohilwe, Sphiwe, Inge, \& Sumner, 2018). Namun sekitar dua pertiga orang dengan skizofrenia di negara berpenghasilan menengah kebawah tidak memiliki akses ke segala bentuk perawatan kesehatan mental khusus. Orang dengan skizofrenia mungkin mengalami berbagai gangguan yang menyebabkan kesulitan dalam melakukan tugas yang berkaitan dengan kesehatan dan kebersihan pribadi, memelihara rumah tangga, mempertahankan kemandirian finansial dan menjaga hubungan pribadi (Pedersen, Vestergaard,
Nordentoft, Laursen, \& Mors, 2019). Skizofrenia merupakan penyakit mental kronis yang sangat terkait dengan stigma dan diskriminasi. Faktor sosiodemografi dan klinis adalah faktor penyebab stigma dimasyarakat. Rehabilitasi psikososial berperan dalam mengurangi stigma yang dirasakan di pada pasien dengan skizofrenia (Zubaidiah et al., 2020). Akibat dari stigma tersebut, pasien tidak mendapatkan pekerjaan, sehingga yang dilakukan hanya berdiam dirumah dan merokok (Adamkaz, 2020).

Pekerjaan sangat penting dalam mempromosikan pemulihan bagi orang dengan penyakit mental, karena memberikan identitas sosial, perasaan pencapaian pribadi dan, yang paling penting, dikaitkan dengan berkurangnya gejala kejiwaan dan 
penerimaan di masyarakat (Hanisch, Wrynne, \& Weigl, 2017). Konselor puskesmas memainkan peran penting dalam pengobatan multimorbiditas mental dan fisik. Konselor puskesmas juga berperan dalam penghapusan stigma pada masyarakat. Namun demikian, tidak jelas berapa banyak individu dengan skizofrenia menggunakan layanan kesehatan primer dan terlayani di puskesmas (Pedersen et al., 2019).

Hasil studi awal didapatkan sebagian besar pasien skizofrenia terkesan kurang melakukan perawatan diri ditunjukkan dengan rambut yang panjang, dan terkesan kotor. Pakaian yang digunakan tampak tidak layak, serta sebagian besar pasien didapatkan tiduran didalam rumah. Belum kami temukan literature penelitian tentang upaya dan hambatan konselor puskesmas dalam perawatan pasien skizofrenia. Kami tertarik untuk mengetahui upaya dan kendala konselor puskesmas dalam merawat pasien skizofrenia. Penelitian ini bertujuan untuk mengetahui upaya dan kendala konselor puskesmas dalam perawatan pasien skizofrenia.

\section{METODE PENELITIAN}

Metode kualitatif deskriptif digunakan dalam penelitian ini, dimana dilakukan di Kabupaten Madiun desa Pilang Kenceng, pada bulan Januari sampai November 2019. Partisipan berjumlah 4 orang tenaga kesehatan yang bekerja di Puskesmas. Pernyataan dari partisipan di validasi dengan menanyakan pada kader kesehatan desa. Selain itu validasi juga dengan menggunakan dokumen daftar kunjngan pasien ke puskesmas dalam mengambil obat.

\begin{abstract}
Proses pengambilan data menggunakan tehnik in depth interviewing menggunakan pertanyaan terstuktur untuk menanyakan upaya dan kendala konselor puskesmas dalam perawatan pasien skizofrenia.
\end{abstract} (Moleong, 2018). Partisipan dipilih dengan tehnik purposive sampling, dan wawancara dilakukan di puskesmas dengan rata-rata waktu selama 45-90 menit. Trianggulasi sumber dilakukan dengan melihat dokumen rekam medis pasien dipuskesmas, serta dokumen pengajuan pelatihan. Triangulasi metode dilakukan dengan wawancara yang terpisah antar narasumber. Triangulasi peneliti dilakukan dengan curah pendapat antar peneliti dengan melihat data yang didapat. Triangulasi teori dengan mencari artikel terkait skizofrenia pada pangkalan data jurnal ebscho dan science direct. Peneliti membandingkan hasil penelitian dengan jurnal yang didapat (Moleong, 2018).

\section{HASIL PENELITIAN}

Partisipan pada penelitian ini yaitu 4 orang konselor skizofrenia dimana terdiri dari 2 orang perawat, 1 orang dokter, dan 1 orang kepala puskesmas. Hasil interpretasi tema menunjukkan bahwa terdapat 6 tema yaitu pengajuan pelatihan, optimaliasasi peran masyarakat, deteksi dini, pemberian pengobatan, penyuluhan, dan kendala konselor

\section{Tema 1 : Pengajuan Pelatihan}

Upaya pengajuan pelatihan oleh konselor terdiri dari pengajuan pelatihan ke disnaker dan dinkes serta lembaga swadaya masyarakat (LSM) akan tetapi tidak terlaksana seperti digambarkan pada pernyataan berikut ini : 
"Pernah mengajukan proposal kerjasama dengan dinas tenaga kerja dan dinkes tapi tidak berjalan"

"Pernah minta LSM untuk memberikan pelatihan pada pasien jiwa akan tetapi belum terlaksana"

\section{Tema 2 : Optimalisasi Peran Masyarakat}

Upaya konselor dalam

optimalisasi peran masyarakat di wujudkan dalam optimalisasi peran kader, dimana program kader skizofrenia tidak berjalan ketika pendanaan tidak ada sebagaimana pernyataan berikut :

“.. Kadernya ada, penyuluhan juga dilakukan, tapi ketika dananya tidak ada program tidak jalan.."

".. Kader biasanya mengambilkan obat punya tetangganya.."

\section{Tema 3 : Deteksi Dini}

Upaya konselor didalam perawatan pasien skizofrenia yaitu melakukan deteksi dini, seperti tercermin pada pernyataan berikut :

"..Kita sudah melakukan deteksi dini pakai instrumen kuisioner, hasilnya sudah ada.."

\section{Tema 4 : Pemberian Pengobatan}

Pada tema 4 yaitu pemberian pengobatan. Pemberian pengobatan merupakan salah satu tugas fasilitas kesehatan primer, sehingga konselor berupaya setiap pasien mendapatkan pengobatan sebagaimana tergambar berikut:

"..Konselor yag ada di puskesmas memberikan obat dan mencatatnya.."

“..Dulu obat diantar ke rumah pasien jika dia tidak datang ke puskesmas, sekarang tidak lagi.."

\section{Tema 5 : Penyuluhan}

Pada tema yang ke 5 ini didapatkan suatu informasi dimana penyuluhan sudah dilakukan, akan tetapi memang kesadaran masyarakat rendah, sebagaimana tercermin pada keadaan berikut ini :

"..Penyuluhan sudah dilakukan, akan tetapi memang kesadaran masyarakat rendah.."

\section{Tema 6 : Kendala Konselor}

Kendala konselor didalam merawat pasien skizofrenia yaitu dukungan dinas terkait, peran masyarakat, dana, kemiskinan masyarakat, dan pengetahuan masyarakat, seperti yang ditunjukkan pada pernyataan berikut :

"...Tidak ada respon ketika mengajukan proposal pelatihan kerja pasien..."

“..Tetangga atau masyarakat terkesan biasa menghadapi pasien jiwa, tidak ada upaya perbaikan kondisi.."

"..Dana yang dipunyai terbatas, jika dana habis program tidak jalan.."

"..Masyarakat hidupnya sudah susah, jadi cenderung memikirkan diri sendiri..."

"....Masyarakat menganggap tidak marah saja sudah sembuh..."

“....Meski tidak produktif, tidur saja sudah dianggap bagus.."

\section{PEMBAHASAN}

Pada tema 1 didapatkan bahwa upaya pengajuan pelatihan oleh konselor tidak terlaksana. Hasil penelitian menunjukkan bahwa pekerjaan adalah elemen kunci dalam pemulihan dari skizofrenia. Namun $60 \%-80 \%$ orang dengan skizofrenia tidak terlibat dalam pekerjaan. Masyarakat tidak percaya proses pemulihan sudah dilakukan di rumah sakit, dan sekarang pasien bisa 
beraktifitas lagi (Lipskaya-velikovsky, Kotler, \& Jarus, 2016).

Apabila dihubungkan dengan tema 6 yang didapatkan data kendala konselor didalam merawat pasien skizofrenia yaitu dukungan dinas terkait, peran masyarakat, dana, dan kemiskinan masyarakat, maka akan sulit bagi pasien skizofrenia didalam mendapatkan pekerjaan dan beraktifitas normal. Kondisi ini menyebabkan pasien skizofrenia berpotensi mengalami relaps. Relaps dapat terjadi karena faktor ketidakpatuhan pasien pada pengobatan, ekonomi, mendapat perlakuan kasar, perasaan marah yang diekspresikan secara berlebihan oleh keluarga, pertengkaran yang tiada henti dengan adik atau kakak kandung, dan permasalahan yang berkepanjangan dengan pasangan hidup (Amelia \& Anwar, 2013).

Tema ke dua didapatkan upaya konselor dalam optimalisasi peran masyarakat di wujudkan dalam optimalisasi peran kader, dimana program kader skizofrenia tidak berjalan ketika pendanaan tidak ada. Peran kader yang sedikit ini tidak lepas dari stigma bahwa salah satu penyakit yang sulit disembuhkan yaitu skizofrenia (Zubaidiah et al., 2020). Pandangan ini telah terinternalisasi pada sikap masyarakat terhadap penderita skizofrenia. Pandangan ini membentuk stigma dan terbangun pemahaman sosial bahwa pasien skizofrenia harus dikucilkan (Rasdale, Warman, \& Phalen, 2018).

Upaya pertama yang harus dilakukan untuk optimalisasi peran kader adalah penghapusan stigma. Stigma merupakan konsep multi komponen yang melibatkan proseslabeling, stereotyping, dan pengucilan secara sosial, kehilangan status, diskriminasi, semuanya berperan dalam kekuatan yang berbeda beda antara pemberi stigma dan kelompok yang terstigma (Capar \& Kavak, 2019). Stigma yang berkembang dimasyarakat tentang perilaku pasien skizofrenia, menyebabkan pasien mengalami masalah dalam memperoleh hak pribadinya (Carmona, Gómez, \& Rodes, 2019).

Tema ketiga yaitu deteksi dini. Deteksi dini diperlukan agar pengobatan yang dilakukan terhadap penderita skizofrenia bisa menghasillkan pemulihan yang lebih cepat. Deteksi dini dapat mencegah pasien skizofrenia larut mengikuti halusinasi atau perilaku kekerasan yang dilakukan (Halperin \& Falk-kessler, 2020).

Tema ke empat adalah upaya pemberian pengobatan. Para ahli berpendapat bahwa skizofrenia disebabkan oleh kelebihan dopamin dalam otak sehingga mengganggu proses berpikir penderita. Terapi farmakologis yang diberikan pada pasien digunakan sebagai upaya untuk menurunkan kelebihan dopamin (Pedersen et al., 2019).

Orang dengan skizofrenia (ODS) tentunya akan mengonsumsi obat dalam waktu yang lama. Skizofrenia yang dapat diidentifikasi pada periode awal, maka terapi farmakologis dapat dilakukan dalam waktu dua tahun. Evalusi penghentian terapi akan dilakukan setelahnya, dimana dokter akan menilai perilaku pasien. Bila penderita masih mengalami kekambuhan, maka dokter perlu mengevaluasi setelah lima tahun. Selain obat, penderita juga memerlukan terapi psikososial misalnya pemberian bekal keterampilan agar ia siap kembali 
ke lingkungan sosialnya (Hidayati, 2012; Zubaidiah et al., 2020).

Tema yang ke 5 yaitu upaya penyuluhan sudah dilakukan, akan tetapi memang kesadaran masyarakat rendah. Hasil penelitian Manurung (2019) menunjukkan bahwa kemampuan perawatan keluarga dan masyarakat didalam perawatan pasien skizofrenia dipengaruhi oleh koping masyarakat. Ketika keluarga dan masyarakat beranggapan skizofrenia adalah penyakit yang memalukan dan membawa aib bagi keluarga, maka pasien akan dilakukan isolasi bahkan memasungnya. Apabila masyarakat menganggap skizofrenia adalah hal biasa, maka pasien hanya dibiarkan saja, asalkan tidak mengganggu (Dalimunthe, 2019).

Data pada tema 5 selaras dengan tema 6 dengan pernyataan bahwa :

"....Masyarakat menganggap tidak marah saja sudah sembuh..."

"....Meski tidak produktif, tidur saja sudah dianggap bagus.."

Pernyataan ini menunjukkan bahwa masyarakat sudah menganggap biasa kondisi skizofrenia pada pasien, sehingga upaya masyarakat tidak optimal. Pada dasarnya tingkat ketergantungan pasien terhadap pemenuhan kebutuhan dasarnya pada keluarga dan masyarakat cukup tinggi (Al \& Hasan, 2019).

Tema 6 didapatkan kendala konselor didalam merawat pasien skizofrenia yaitu dukungan dinas terkait, peran masyarakat, dana, kemiskinan masyarakat, dan pengetahuan masyarakat. Keseluruhan sub tema telah dibahas pada tema-tema sebelumnya. Pada dasarnya perlu dukungan berbagai pihak dalam perawatan pasien skizofrenia.

\section{KESIMPULAN DAN SARAN}

Kesimpulannya yaitu upaya konselor dalam perawatan pasien skizofrenia yaitu pengusulan program pelatihan, mengoptimalkan peran masyarakat, deteksi dini, memberikan pengobatan, dan pemberian konseling. Kendala yang dihadapi oleh konselor yaitu dukungan dinas terkait, peran masyarakat, dana, kemiskinan masyarakat, dan pengetahuan masyarakat. Perlu sinergi antara masyarakat, konselor, dinas social, dinas tenaga kerja, pengusaha dan berbagai pihak dalam upaya perawatan pasien skizofrenia. Pasien skizofrenia memerlukan pekerjaan dan penghapusan stigma.

\section{DAFTAR RUJUKAN}

Adamkaz. (2020). ISSUES : mental illness. In Harvard Womens Health Watch (pp. 2019-2020). Retrieved from www.health.harvard.edu

Al, A., \& Hasan, H. (2019). The effect of a family intervention on primary caregivers psychological outcomes: Findings from the integrative literature review. Perspect Psychiatr Care, 55(November 2018), 277-290. https://doi.org/10.1111/ppc.12339

Amelia, D. R., \& Anwar, Z. (2013). Relaps Pada Pasien Skizofrenia. Jurnal Ilmiah Psikologi Terapan, 01(01), 53-65.

Capar, M., \& Kavak, F. (2019). Effect of internalized stigma on functional recovery in patients. Perspect Psychiatr Care, 55(May 2018), 103-111. https://doi.org/10.1111/ppc.12309 
Carmona, V. R., Gómez, J., \& Rodes, J. E. R. (2019). Employment Support Needs of People with Schizophrenia: A Scoping Study. Journal of Occupational Rehabilitation, 29(1), 1-10.

Dalimunthe, D. Y. (2019). Hubungan Mekanisme Koping Keluarga dengan Kemampuan Keluarga Merawat Pasien Skizofrenia di Poliklinik Jiwa RSJ Prof Dr M Ildrem Medan. Poltekkes Medan, 5(1), 1-9.

Halperin, L., \& Falk-kessler, J. (2020). Schizophrenia Spectrum Disorders: Linking Motor and Process Skills, Sensory Patterns, and Psychiatric Symptoms Schizophrenia Spectrum Disorders : Linking Motor and Process Skills , Sensory. The Open Journal of Occupational Therapy, 8(1), 1-13.

Hanisch, S. E., Wrynne, C., \& Weigl, M. (2017). Perceived and actual barriers to work for people with mental illness. Journal of Vocational Rehabilitation, 46(1), 19-30.

https://doi.org/10.3233/JVR160839

Hidayati, E. (2012). Pengaruh Terapi Kelompok Suportif Terhadap kemampuan Mengatasi Perilaku Kekerasan Pada Pasien Skizofrenia Di RSJ Dr Amino Gondohutomo Kota Semarang. Jurnal Unimus, 304-312.

Lipskaya-velikovsky, L., Kotler, M., \& Jarus, T. (2016). Factors discriminating employment status following in-patient evaluation among persons with schizophrenia. IOS Press, 53, 469-478. https://doi.org/10.3233/WOR152178

Pedersen, H. S., Vestergaard, M., Nordentoft, M., Laursen, T. M., \& Mors, O. (2019). Schizophrenia and attendance in primary healthcare: a population-based matched cohort study. Scandinavian Journal Of Prymary Health Care, 37(3), 358-365.

Rasdale, Warman, \& Phalen. (2018). An examination of perceptions of individuals with an intellectual disability, with and without comorbid schizophrenia: effects of labels on stigma. Journal of Intellectual Disability Research, 62(6), 544-557. https://doi.org/10.1111/jir.12494

Sumner, C. B., Selohilwe, O., Sphiwe, M., Inge, M., \& Sumner, C. B. (2018). Process Evaluation of a Pilot Intervention for Psychosocial Rehabilitation for Service Users with Schizophrenia in North West Province, South Africa. Community Mental Health Journal, 54, 1089-1096.

Zubaidiah, S., Jaapar, S., Rasdi, N., Othman, Z., Hussin, S., \& Mohammad, J. A. (2020). The Effect of Psychosocial Rehabilitation on Perceived Stigma among Patients with Schizophrenia in Kelantan , Malaysia. International Medical Journal, 27(1), 8-12. 